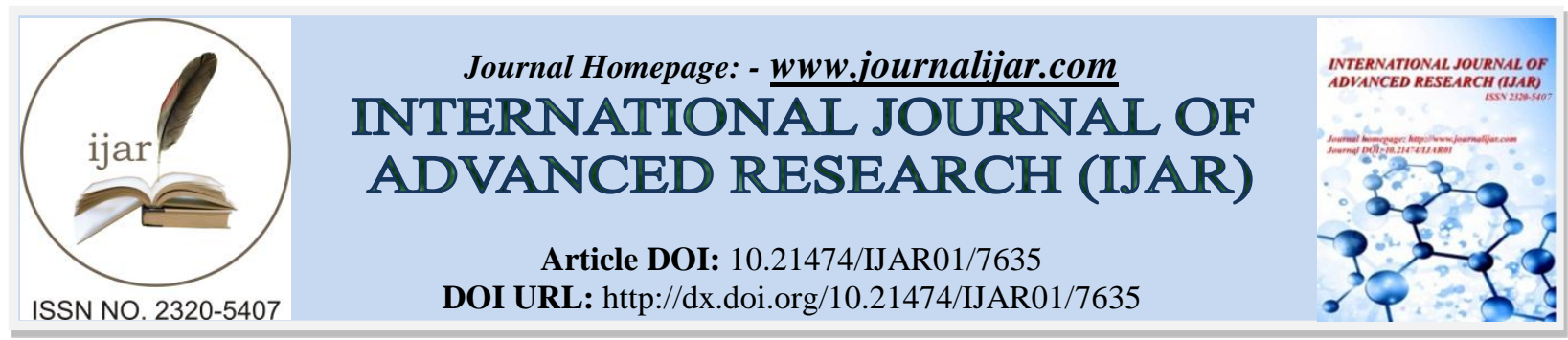

RESEARCH ARTICLE

\title{
VISCOELASTIC PROPERTIES OF HARD AND SOFT DENTURE BASE RELINE MATERIALS.
}

\author{
Sherihan M. Eissa ${ }^{1}$, Dalia Y. Zaki ${ }^{2}$, Asmaa N. Elboraey ${ }^{1}$, Amani R. Moussa ${ }^{3}$. \\ 1. Researcher, Fixed \& Removable Prosthodontic Dep., National Research Centre (NRC), Giza, Egypt. \\ 2. Ass Prof, Restorative \& Dental Materials Dep, National Research Centre (NRC), Giza, Egypt. \\ 3. Ass Prof, Fixed \& Removable Prosthodontic Dep., National Research Centre (NRC), Giza, Egypt.
}

\section{Manuscript Info}

Manuscript History

Received: 24 June 2018

Final Accepted: 26 July 2018

Published: August 2018

Key words:

Viscoelastic, denture reline, hard and soft reline material

\section{Abstract}

Background: Reline materials are integral part in management of patients wearing removal complete dentures.

Objectives: The objective of this study was to assess and compare the viscoelastic properties of the permanent hard acrylic resin reline and silicone based soft liner materials.

Materials and methods: Rectangular specimens of the hard reline (Acrostone, Dental \& Medical Co, Egypt) and silicone liner (Molloplast B, Detax Karl Huber GmbH \& Co., Karlsruhe, Germany) materials were fabricated according to the manufacturer's instructions of each material. The viscoelastic properties regarding ( $G^{\prime}, G^{\prime}$ and tan $\delta$ ) were measured using visco-elastometer under shear mode of deformation at a frequency of $1 \mathrm{~Hz}$ at $37^{\circ} \mathrm{C}$.

Results: The hard resin reline material showed higher statistically significant mean values $(\mathrm{P}<0.05)$ regarding the three measured parameters. However, both materials had $\tan \delta$ values approaching zero.

Conclusions: within the limitation of this study the following could be concluded: Both materials had cushioning effect and the ability to dissipate energy into heat. However, hard resin reline absorb more energy consequently, it reduces stress transmitted to alveolar mucosa more than that of silicone based soft liner.

Copy Right, IJAR, 2018,. All rights reserved.

\section{Introduction:-}

Although, implant prosthesis is recognized as standard of care for completely edentulous individuals [1]; the high cost, medical conditions and anatomical complications are major limiting factors [2], for such treatment modality. Therefore, the necessity for complete dentures as treatment choice will continue. One of the main drawbacks associated with the use of complete dentures is continuous alveolar bone resorption, resulting in; flat ridges, atrophy of mucosa, pain and loss of denture retention and stability [3].

Denture base relining or construction of new dentures [4] is mandatory to restore adaptation to the underlying mucosa and / or to alleviate pain and discomfort caused by ill-fitting dentures. Relining procedures is more affordable and less time consuming for most cases. The dentures to be relined should be satisfactory regarding; occlsion, contour and extension, in addition to esthetics to justify its continued use [5] 
Reline materials are of two types: hard resins reline and soft liners. Soft liners are classified into temporary and permanent liners [6]. Permanent soft liners are either acrylic resins or silicone heat polymerized materials. The latter are widely used owing to their better durability [7].

Clinically, hard resins reline are applied to improve fit, retention and stability of ill-fitting complete dentures [8]. while soft liners are used in cases suffering from thin mucosa, and/ or resorbed ridge. Due to their cushioning effect, they are able to alleviate pain and discomfort. [9].

Dentures could be relined using either direct (chair side reline) or indirect (laboratory) techniques. Autopolymerized materials are used for the direct method, while, heat polymerized materials are used for the indirect method. Despite of the low cost, the ease of fabrication and being more appropriate for the patient [5], the indirect method is more advantageous; because of their better mechanical properties and the controllable thickness of the reline material that could be easily obtained [6].

In literature; numerous studies evaluated the physical, static mechanical properties and adhesion of reline materials to denture base resins [4,5,10], However, during function; relined dentures are exposed to cyclic loading during mastication and swallowing [11]. Accordingly, it is important to assess their characteristics and response to functional stresses.

Dynamic mechanical analysis (DMA); is a reliable method utilized to measure the viscoelastic properties of polymer materials over a wide range of frequencies and temperature. Information about the durability and performance of the tested material could be obtained by subjecting the material to frequencies similar to that produced during mastication using the DMA method [12]. The three important rheological measurements of DMA, (storage modulus $\left(\mathrm{G}^{\prime}\right)$, loss modulus $\left(\mathrm{G}^{\prime \prime}\right)$, and damping factor $(\tan \delta)$ ) describe the elasticity, the viscosity and the cushioning effect of the material against masticatory force respectively [6]. To ensure the clinical relevance of the reline materials; the viscoelastic properties are to be considered. Therefore; the aim of this study was to assess and compare the viscoelastic properties of the permanent hard resin reline and silicone based soft liner materials.

\section{Materials and Methods:-}

The two reline materials, description and manufacturers are listed in table (1).

\section{Specimen's preparation:}

Twenty rectangular shaped specimens $(1 \mathrm{~mm} \times 30 \mathrm{~mm}$ x $10 \mathrm{~mm})$ of the two reline materials $(\mathrm{n}=10)$ were fabricated. The specimens were prepared by investing rectangular stainless-steel plates into dental stone (Gypsano, united Co., Gypsum industries, Egypt). Each reline material was proportioned, mixed, packed at dough stage into the prepared stone molds and then processed according to the manufacturer's instructions of each material.

Table 1:-The two reline materials used in the resent study Commercial name

\begin{tabular}{|l|l|l|}
\hline & Description & Manufacture \\
\hline Acrostone & $\begin{array}{l}\text { Heat cured hard reline based on Poly } \\
\text { Methyl Methacrylate. } \\
\text { (powder \& liquid system) }\end{array}$ & $\begin{array}{l}\text { Acrostone, Dental \& Medical Co, } \\
\text { Egypt) }\end{array}$ \\
\hline Molloplast B & $\begin{array}{l}\text { Heat cured permanent } \\
\text { Silicon based permanent soft liner } \\
\text { (one paste system) }\end{array}$ & $\begin{array}{l}\text { Detax Karl Huber GmbH \& } \\
\text { Co., Karlsruhe, Germany }\end{array}$ \\
\hline
\end{tabular}

\section{Dynamic mechanical thermal analysis}

The viscoelastic properties were measured using viscoelastometer (Anton Paar, MCR301 SN80218500, Austria, Europe) based on a non-resonance-forced vibration principle according to ISO (4664-112). Specimens were set in a shearing jig and tested at a frequency of $1 \mathrm{~Hz}$ at $0.7 \%$ strain [13] under shear mode of deformation, at $37^{\circ} \mathrm{C}$. The material's response regarding storage modulus $\left(G^{\prime}\right)$, shear loss modulus $\left(G^{\prime \prime}\right)$, and loss tangent $(\tan \delta)$, was recorded. Statistical analysis was performed using SPSS software package (Statistical Package for Social Sciences, version 10, SPSS Inc., Chicago, IL, USA). Comparisons of data were made by Independent $t$ test at $\mathrm{P}<0.05$ level to establish significance of differences. 


\section{Results:-}

The results of viscoelastic properties of the two reline materials are listed in table (2) and shown in figure (1and 2). The hard resin reline material showed higher statistically significant mean values $(\mathrm{P}<0.05)$ regarding the three measured parameters ( $\mathrm{G}^{\prime}, \mathrm{G}^{\prime}$ and $\left.\tan \delta\right)$.

Table 2:-Mean and standard deviation values $(\mathrm{Pa})$ of storage modulus, loss modulus and damping factor of both groups Storage Modulus

\begin{tabular}{|l|l|l|l|}
\hline \multicolumn{2}{|c|}{ Loss Modulus } & Damping Factor \\
\hline Hard resin reline & $13.9 \times 108 \pm 4.41 \times 108$ & $1.2 \times 108 \pm .3 \times 108$ & $0.087 \pm 0.0042$ \\
\hline Soft silicone liner & $0.014 \times 108 \pm 0.00086 \times$ & $0.001 \times 108 \pm 0.00005 \times$ & $0.07 \pm 0.001$ \\
& 108 & 108 & $0.00 * *$ \\
\hline P-value & $0.00^{* *}$ & $0.00^{* *}$ & 0.06 \\
\hline
\end{tabular}

M; Mean, SD; Standard deviation, P; Probability Level

**significant difference

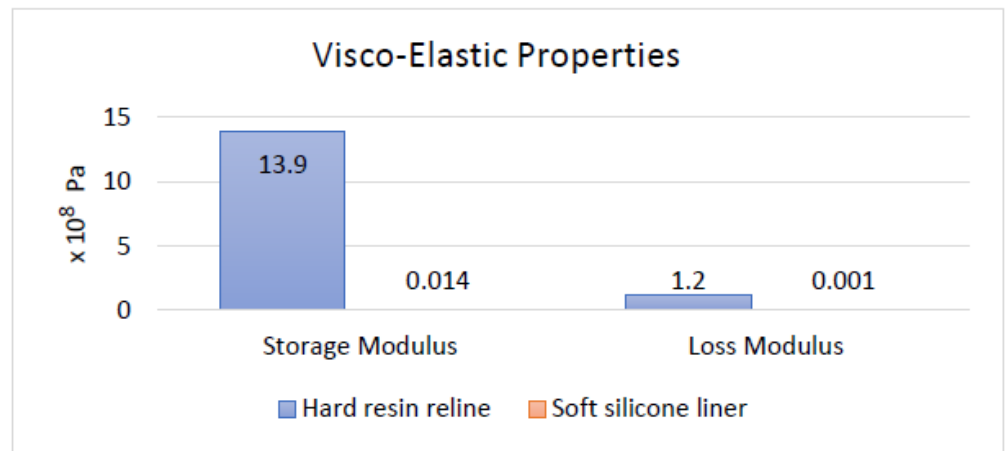

Fig. 1:-Bar chart of storage and loss moduli of hard and soft reline materials.

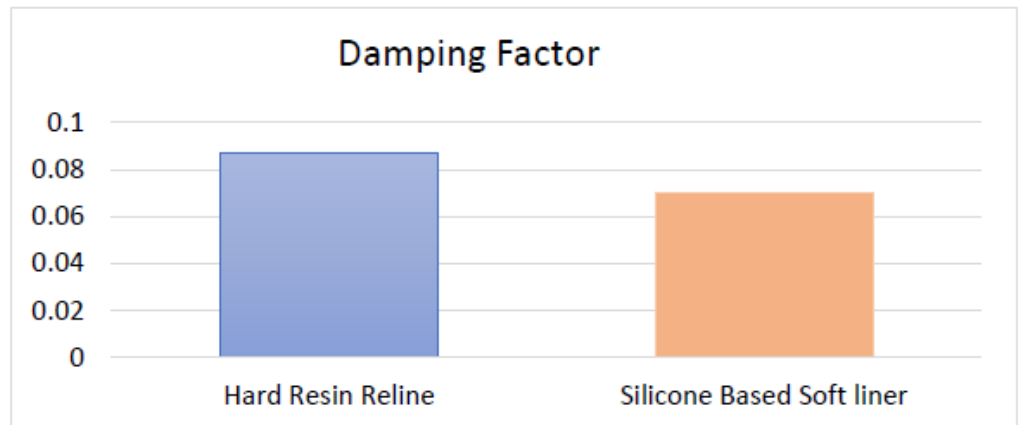

Fig. 2:-Bar chart of damping factor of hard and soft reline materials.

\section{Discussion:-}

Reline materials are integral part in management of patients wearing removal complete dentures. They are applied to the intaglio surface of the denture to improve its adaptation to the underlying structures [14].

To understand and relate the viscoelastic response of reline materials to its clinical usefulness, DMA based on nonresonance forced vibration was used to assess these properties in the present study. A constant frequency of $1 \mathrm{~Hz}$ was applied to simulate the masticatory rhythm, and at $37 \pm 1 \mathrm{oC}$ to represent the average temperature in the oral cavity [12]. Silicone based soft liner is known for its durability and the ability to maintain its resiliency for extended periods [15]. The higher significant $\mathrm{G}^{\prime}$ and $\mathrm{G}^{\prime \prime}$ values recorded for the hard reline material indicates its higher rigidity, while silicone soft reline type showed more flexibility. According to Murata et al, 2007 [16], an ideal hard resin reline should have high stiffness $\left(\mathrm{G}^{\prime}\right)$, moderate deformation with stress $\left(\mathrm{G}^{\prime \prime}\right)$, but low damping factor ( $\tan \delta$ ), as it is desirable for the material to return to its original shape shortly after the load is removed. The result of the present study is in agreement with studies conducted by (Murata et al, 2002) [13], and (Murata et al, 2008) [6]. 
The damping factor (Tan $\delta$ ) which is the ratio between $G^{\prime \prime} / G^{\prime}$ is an important measure in determining the material behavior [17]. Both tested materials showed $\tan \delta$ values approaching zero indicating the high cushioning effect, the ability to dissipate energy into heat, and great molecular mobility, with higher effects revealed by the hard resin reline type. Therefore; the hard resins reline type proved to have greater ability to absorb energy, relieve stress under masticatory force and reduce the stress transmitted to alveolar mucosa than the soft relining type. The relief of stresses improves the masticatory function and provides better masticatory performance for direct crushing of food. However, according to (Villar et al, 2003) [18] clinically, the softer the liner the more compliant and comfortable for patient, especially with thin ridges and sore mucosa.

\section{Conclusions:-}

Within the limitations of this in vitro study it was concluded that:

1. Both materials had $\tan \delta$ values approaching zero indicating the high cushioning effect and had the ability to dissipate energy into heat however, the ability of hard resin reline to absorb energy and reduce the stress transmitted to alveolar mucosa is greater than that of silicone based soft liner.

2. The silicone based soft liner is more compliant in complete denture patients suffering from thin wiry ridge and sore mucosa.

\section{Conflict of interest}

The authors declare no conflict of interest

\section{Acknowledgment:-}

None

\section{Reference:-}

1. Feine JS, Carlsson GE, Awad MA, Chehade Q, Duncan J, Gizani S,: The Mc Gill consensus statement on overdentures. Mandibular two- implant overdentures as first choice standard of care for edentulous patients. Int J Oral Maxillofacial Implants (2002); 17: 601-602.

2. Balaji A, Mohamed J B and Kathiresan R.: A Pilot Study of Mini Implants as a Treatment Option for Prosthetic Rehabilitation of Ridges with Sub-Optimal Bone Volume. J. Maxillofacial. Oral Surg. (2010); 9; 4:334-38.

3. Takase K, Watanabe I, Kurogi T. and Murata H.: Evaluation of glass transition temperature and dynamic mechanical properties of auto-polymerized hard direct denture reline resins. Dental Materials Journal (2015); 34;2: 211-218.

4. Ahmad F. and Yunus N.: Shear Bond Strength of Two Chemically Different Denture Base Polymers to Reline Materials. Journal of prosthodontics (2009); 18;7 :596-602.

5. Leles C. R., Machado A. L., Vergani C. E., Giampaolo E. T. \& Pavarina A. C.: Bonding strength between a hard chairside reline resin and a denture base material as influenced by surface treatment Journal of Oral Rehabilitation (2001) 28; 1153-1157.

6. Murata H, Hamada T and Sadamori S.: Relationship between viscoelastic properties of soft denture liners and clinical efficacy Japanese Dental Science Review (2008) ;44; 128-132.

7. Machado AL, Breeding LC and Puckett AD: Effect of microwave disinfection on the hardness and adhesion of two resilient liners. J Prosthet Dent (2005) 94:183-189.

8. Van Meegen HG. and Kalk W.: Improvement of a removable complete denture by relining or rebasing. Ned Tijdschr Tandheelkd. (2011);118; 11:545-51.

9. Hamada T. and Murata H.: Denture lining. Tokyo; Dental Diamond Co.:(2001):68-76 (in Japanese).

10. Jin, C., Nikawa H., Makihira S, Hamada T., Furukawa M and Murata H.: Changes in surface roughness and color stability of soft denture lining materials caused by denture cleansers. J Oral Rehab. (2003), 30: 125-130.

11. Murata H, Taguchi N, Hamada T and McCabe JF.: Dynamic viscoelastic properties and the age changes of long-term soft denture liners. Biomaterials (2000); 21: 1421-1427.

12. Santawisuk W1, Kanchanavasita W, Sirisinha C and Harnirattisai C.: Dynamic viscoelastic properties of experimental silicone soft lining materials. Dent Mater J. (2010);29; 4:454-60.

13. Murata, H.; Taguchi, N.; Hamada, T.; Kawamura, M. and McCabe, J.F.: Dynamic viscoelasticity of soft liners and masticatory function. J. Dent. Res. (2002);81, 123-128.

14. Mese A. and Guzel KG.: Effect of storage duration on the hardness and tensile bond strength of silicone- and acrylic resin-based resilient denture liners to a processed denture base acrylic resin. J Prosthet Dent (2008); 99:153-9. 
15. Botega DM, Sanchez JL, Mesquita MF, Henriques GE and Consani RL.: Effects of thermocycling on the tensile bond strength of three permanent soft denture liners. J Prosthodont (2008); 17:550-554.

16. Murata H, Seo RS, Hamada T, Polyzois GL and Frangou MJ.: Dynamic mechanical properties of hard, direct denture reline resins. J Prosthet Dent. (2007);98:319-26.

17. Tolidis K, Papadogiannis D and Gerasimou P.: Dynamic and static mechanical analysis of resin luting cements. J The Mech Behav Biomed Mater (2012); 6:1-8.

18. Villar A.: Clinical evaluation of a new resilient denture liner: ( $\mathrm{Pt}$ 1) compliance and color evaluation. J Prosthodont (2003), 12: 82-89. 